\title{
Article
}

\section{Metabolomic characterization of olive xylem sap reveals differences according to plant age and genotype}

\author{
Manuel Anguita-Maeso 1, Carmen Haro 1, Miguel Montes-Borrego ${ }^{1}$, Leonardo De La Fuente ${ }^{2}$, Juan A. Navas- \\ Cortés ${ }^{1, *}$ and Blanca B. Landa ${ }^{1, *}$ \\ ${ }^{1}$ Department of Crop Protection, Institute for Sustainable Agriculture, Spanish National Research Council \\ (CSIC), Córdoba, Spain, \\ 2 Department of Entomology and Plant Pathology, Auburn University, Auburn, AL, USA. \\ *Correspondence: j.navas@csic.es; $\underline{\text { blanca.landa@csic.es }}$
}

\begin{abstract}
Vascular pathogens are the causal agents of main diseases threatening the health and growth of olive crops worldwide. The use of endophytic microorganisms represents a challenging and promising strategy for management of vascular diseases in olive. Although current research has been focused on analyzing the structure and diversity of the endophytic microbial communities inhabiting the olive xylem, the characterization of this ecological niche has been overlooked and to date remain unexplored, despite that the characterization of the xylem sap composition is essential to unravel the nutritional requirements of xylem-limited microorganisms. In this study, branches from plantlets and adult olive trees of cultivars 'Picual' and 'Arbequina' were selected to characterize the chemical composition of olive xylem sap extracted using a Scholander pressure chamber. Metabolome and ionome analyses of xylem sap were performed by proton nuclear magnetic resonance (NMR) spectroscopy-based and by inductively coupled plasma with optical emission spectroscopy (ICP-OES), respectively. Olive xylem sap metabolites included a higher relative percentage of sugars $(54.35 \%)$, followed by alcohols $(28.85 \%)$, amino acids $(8.01 \%)$, organic acids $(7.68 \%)$ and osmolytes $(1.12 \%)$. Within each of these groups, the main metabolites in the olive xylem sap were mannitol, ethanol, glutamine, acetate and trigonelline, whereas $\mathrm{K}$ and $\mathrm{Cl}^{-}$were the main element and inorganic anion, respectively. Metabolomic profile varied when comparing olive plant age and genotype. The levels of glucose, fructose, sucrose and mannitol, choline, $\mathrm{B}$ and $\mathrm{PO}_{4}{ }^{3}$ were significantly higher in adult trees than in plantlets for both olive genotypes, whereas $\mathrm{NO}_{3}$ and $\mathrm{Rb}$ content showed the opposite behavior. On the other hand, levels of aspartate, phenylalanine and Na were significantly higher in 'Picual' than in 'Arbequina' whereas Fe showed the opposite behavior but only for adult trees. Non-supervised hierarchical clustering analysis separated xylem sap composition firstly according to the plant age and then by the olive cultivar. Supervised PLS-DA analysis revealed that B, ethanol, Fe, Fructose, glucose, mannitol, sucrose and $\mathrm{Sr}$ were the most significative compounds discriminating adult trees from plantlets, whereas asparagine, aspartate, glutamate and phenylalanine or aspartate, arginine, ethanol and Sr were the most contributory compounds in the discrimination of both olive genotypes for adult trees or plantlets, respectively. Knowledge of the chemical composition of xylem sap will lead to a better understanding of the complex nutritional requirements of olive xylem-inhabiting microorganisms, including its vascular pathogens, and would allow the design of artificial growing media to improve culturing the olive microbiome.
\end{abstract}

Keywords: olive; xylem sap; metabolomics; plant age; genotype. 


\section{Introduction}

Olive tree (Olea europaea L.) is one of the most important cultivated trees in the Mediterranean Basin due to the numerous beneficial health properties of olive oil which plays a central role in the Mediterranean diet [1]. The wide use of products derived from olive trees such as table olives and olive oil soaps, cosmetics, etc., is contributing to an increase in the area under olive cultivation and to boosting the economic importance of the olive tree worldwide. The European Union is the main global producer of olive oil with 2.2 Mt, with Spain being the major provider with 1.6 Mt in the 2018/19 season (IOC, www.internationaloliveoil.org).

Olive trees are of great cultural and economic value, but they also exhibit several significant environmental attributes which allow them to survive on poor, shallow and dry soils. These attributes include an extensive root system that promotes drought resistance as well as high adaptability to unfavorable environments including mountain slopes and hillsides where olive roots serve to limit soil erosion and increase nutrient retention [2,3]. In addition, olive crops have been identified as important habitats for rich ground flora and fauna where pollinators play an essential role in the maintenance of ecosystem diversity [4]. These reasons outstand the importance of olive crop as an economic, environmental and cultural symbol across the Mediterranean region and reinforce the need of its maintenance and preservation for future generations. However, nowadays its viability and survival as a main crop is seriously threatened by vascular plant pathogens such as the soil-borne fungus Verticillium dahliae and the bacterium Xylella fastidiosa. Both pathogens colonize the vascular bundles of the xylem obstructing the sap flow, leading to wilting of plant tissue, and ultimately may also cause the death of the tree resulting in heavy environmental and economic losses in areas where those pathogens are endemic or have emerged as new outbreaks [5,6].

Xylem vessels play a decisive role for plant growth maintenance providing a main route and a very refined plumbing system for the circulation of micro and macronutrients derived from xylem sap. Indeed, xylem transport of solutes is essential for long and short distance redistribution of nutrients within the host plant which is driven by hydrostatic pressure and water potential [7]. This nutrient flow in the xylem from roots to shoots ensure controlled loading or unloading of ions and metabolites in the xylem and their effective translocation to the required and localized area [8]. Consequently, the characterization of xylem sap composition is essential to obtain information for understanding nutrient fluxes and dynamics which are crucial for maintenance of plant responses and microbial interactions within the xylem that might result in host plant defense reactions against vascular wilt pathogens [9].

Xylem sap contains a wide range of compounds beyond water and minerals. In fact, several studies have revealed that these compounds include amino acids [10,11], organic acids $[12,13]$, vitamins and metabolites [14,15]. Nevertheless, xylem sap composition does not remain constant in the host plant and it can be influenced by diverse factors such as soil water content [16,17], method of xylem sap collection [18], type of organs selected [19], presence of rootstocks and interstocks [20], and incidence of microbial interactions including infection by plant pathogens [21,22], among others. Additionally, the age of the host plant and seasonal changes are factors affecting xylem sap composition [23-25]. Several studies have characterized the xylem sap composition of woody plant species [e.g., 22,26-29]. However, to our knowledge, only one study has characterized the xylem sap composition of olive trees [30] despite of being one of the most remarkable tree crops in the Mediterranean Basin.

In this work, we have characterized for the first time the xylem sap chemical composition of the two olive genotypes most widely cultivated in Spain and provide new knowledge on the changes in their metabolomic and ionomic profile according to the plant age and the olive genotype. The characterization of xylem sap composition from olive trees will help to improve our understanding of the nutritional requirements for growth 
of xylem-inhabiting microorganisms (including those nonculturable yet) that may lead to design suitable culture media as a first step to isolate or favor the growth of potential endophytic microorganisms that can be exploited as biological control agents against main vascular pathogens in olive.

\section{Materials and Methods}

\subsection{Olive plant material and sampling}

Olive plants from cultivars 'Picual' and 'Arbequina' of different age were used in the study. These olive genotypes are within the most widely cultivated in Spain [31]. Olive adult trees (10-years-old) are grown at an experimental field (sandy loam soil, pH 8.5, $1.4 \%$ organic matter) located at the Alameda del Obispo Research Station near Córdoba (Southern Spain) $\left(37.5^{\circ} \mathrm{N}, 4.8^{\circ} \mathrm{W}\right.$, altitude $110 \mathrm{~m}$ ) belonging to the Institute for Sustainable Agriculture from Spanish National Research Council (IAS-CSIC). The trees are managed according to normal olive cropping practices.

Plantlets (1-year-old) obtained following a standard semi-woody stacking procedure at a commercial olive nursery (Plantas Continental S.A, Córdoba, Spain) were grown in $500 \mathrm{ml}$ pots containing a perlite:coconut fiber:peat (1.5:5:3.5) mixture amended with $1 \%$ of slow release fertilizer (Osmocote ${ }^{\circledR}$ Exact standard 15-9-12+2MgO; ICL Specialty Fertilizers, The Netherlands). Seedling plants were grown for 3 months in a growth chamber adjusted to $22 \pm 2^{\circ} \mathrm{C}, 60-80 \%$ relative humidity and a $14 \mathrm{~h}$ photoperiod of fluorescent light of $360 \mu \mathrm{mol} \mathrm{m} \mathrm{m}^{-2} \mathrm{~s}^{-1}$, were watered as needed and fertilized every two weeks with $100 \mathrm{~mL}$ Hoagland's nutrient solution.

For xylem sap extraction, four terminal 35-cm-long branches (one per tree) from adult trees and the entire canopy of four seedlings from each olive genotype were selected to characterize the chemical composition of olive xylem sap. All pruned branches were placed in sterile plastic bags, sprayed with distilled water and kept in a cold room at $4^{\circ} \mathrm{C}$ to avoid desiccation until sample processing within the same day.

\subsection{Xylem sap extraction}

A Scholander pressure chamber was used to perform xylem sap extraction from xylem vessels with an external port allowing branches inclusion up to $60 \mathrm{~cm}$ long. Xylem sap extraction procedure was described previously in Anguita-Maeso et al. [32]. Briefly, after inserting the branch in the super chamber, $2 \mathrm{~cm}$ of the main stem was debarked and disinfested to avoid microbial contamination of the xylem sap from bark and phloem. The pressure was increased gradually until xylem sap drops were observed, but to a maximum of 25 bars of pressure to avoid external contamination derived from cell rupture.

Xylem sap was collected in a $15 \mathrm{ml}$ sterile Falcon tube placed on ice. An average of $10 \mathrm{ml}$ of xylem sap was collected from adult olive trees, while an average of $5 \mathrm{ml}$ was extracted from olive plantlets. Samples were immediately frozen at $-80^{\circ} \mathrm{C}$ until analysis. One aliquot of the sample was used to determine absence of cytosolic contamination by using the malate dehydrogenase assay kit (Sigma) [27] before sending the samples for metabolomic and ionomic analysis.

\subsection{Metabolomic and ionomic analysis}

Two aliquots of $1 \mathrm{ml}$ each were sent on ice to the Metabolomics and Ionomic Services at the Center for Edaphology and Applied Biology of Segura, CSIC, Spain.

Metabolome analysis of xylem sap was performed by proton nuclear magnetic resonance (NMR) spectroscopy as described in [22]. Briefly, frozen xylem olive sap samples were thawed on ice and 18\% (vol/vol) of D2O (nmr deutero, Germany), containing $0.1 \%$ 3-(trimethylsilyl) propionic acid-d4 sodium salt (TMSP-d4; Sigma Aldrich) was added as chemical shift reference to a final volume of $220 \mu \mathrm{l}$. The NMR spectra were acquired at $298 \mathrm{~K}$ on a Bruker AVIII HD 500 NMR (Bruker Biospin, 
Germany) spectrometer (500.13 MHz for $1 \mathrm{H}$ ) equipped with a $5 \mathrm{~mm}$ CPP BBO cryogenic probe. $1 \mathrm{H}$ spectra were referenced to TMSP signal $(\delta=0.00 \mathrm{ppm})$. Standard onedimensional spectra were acquired at $298 \mathrm{~K}$ using the "noesypr1d" pulse sequence with water presaturation during relaxation delay and mixing time. Acquired spectra consisted of 128 scans, with 65,000 complex data points and a spectral width of 7,211.539 Hz, were processed using Topspin (v3.2; Bruker BioSpin Corp.) and imported to the Chenomx NMR suite (v8.1; Chenomx Inc., Edmonton, Alberta, Canada) for targeted identification and quantification of metabolites present in xylem sap.

Ionome analysis was performed by inductively coupled plasma with optical emission spectroscopy (ICP-OES) as described in de la Rosa et al. [33] using an Optima 4300 DV (Perkin Elmer Instruments; 190 Martinez Rd., Edgewood, NM, 87015; USA). Shortly, after performing the instrument sensitivity and obtain the calibration curve, the following ICPOES parameters were used: nebulizer flow, $0.801 \mathrm{~min}-1$; radio frequency power, 1450; sample introduction, $1.50 \mathrm{ml} \mathrm{min}-1$; flush time, $15 \mathrm{~s}$; delay time, $20 \mathrm{~s}$; read time, $10 \mathrm{~s}$; wash time, $60 \mathrm{~s}$; no internal standards were used and each sample was read in triplicate. On the other hand, xylem sap anion concentration was determined by ion chromatography (Metrohm AG, Herisau, Switzerland) on a Metrosep A Supp 4 analytical column $(4 \times 125$ mm $1.8 \mathrm{~mm} \mathrm{Na2CO3/1.7} \mathrm{mm} \mathrm{NaHCO3} \mathrm{eluent)} \mathrm{as} \mathrm{described} \mathrm{in} \mathrm{Akhtar} \mathrm{et} \mathrm{al.} \mathrm{[34].}$

\subsection{Statistical analyses}

The effects of the olive genotype and plant age on the chemical composition of xylem sap were determined by analysis of variance (ANOVA) using the lineal models function in rstats package in $R$ [41]. The experimental design consisted of a two-way factorial design with plant age and olive genotype as factors. When the interaction plant age $x$ olive genotype was significant $(P<0.05)$ single degree of freedom contrasts were performed to disentangle the differences among treatment combinations. Data of metabolites and ions were unified to $\mu \mathrm{M}$ units prior to logarithm transformation to fulfill ANOVA assumption tested by Shapiro-wilks and Levene's tests using the rtatix and car packages in $\mathrm{R}$, respectively [35,36]. An initial, non-supervised multivariate hierarchical clustering analysis, using Pearson's correlation to measure distance and an average Ward clustering algorithm of all metabolites measured was performed. Then, the supervised clustering method, principal least square-discriminant analysis (PLS-DA) [37], was used to reduce the number of variables (metabolites) and select the most predictive or discriminative to differentiate the xylem sap composition according to the olive plant age, and then within each plant age according to the olive genotype. Both, hierarchical clustering and PLS-DA analyses were performed using MetaboAnalyst 4.0 (http://www.metaboanalyst.ca; [38]).

\section{Results}

\subsection{Metabolite profiles in olive xylem sap}

A total of 30 metabolites were identified in olive xylem sap using NMR including five organic acids (acetate, formic, fumaric, maleic and succinic acids), 15 amino acids (alanine, arginine, asparagine, aspartate, GABA, glutamate, glutamine, isoleucine, leucine, methionine, phenylalanine, proline, threonine, tyrosine, valine), five sugars (glucose, fructose, sucrose, mannitol and myo-inositol), two alcohols (ethanol and methanol), and three other molecules (choline, sarcosine and trigonelline) (Table 1). The vast majority of organic acids, sugars and osmolytes were detected in all samples while amino acids displayed more variability among samples. Thus, the amino acids arginine, asparagine, GABA, methionine and proline were detected in less than half of the samples. In addition, the amino acids arginine, asparagine, aspartate and phenylalanine were detected in a higher number of samples of 'Picual' as compared to 'Arbequina', whereas a higher detection of GABA and Choline was found in adult trees as compared to plantlets (Table 1). 


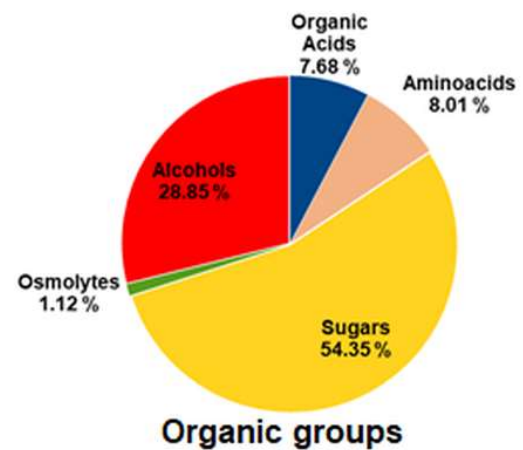

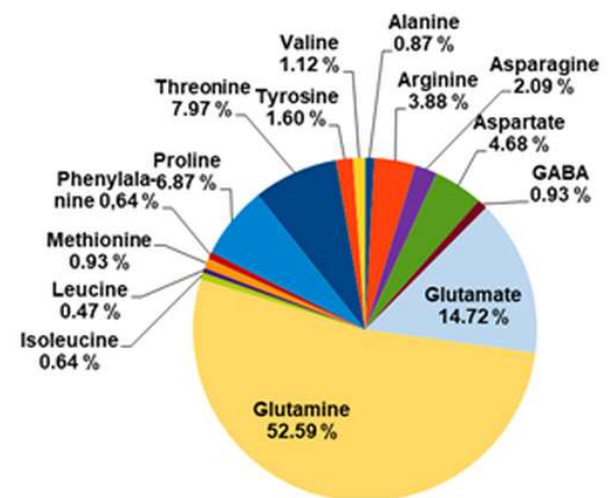

Aminoacids

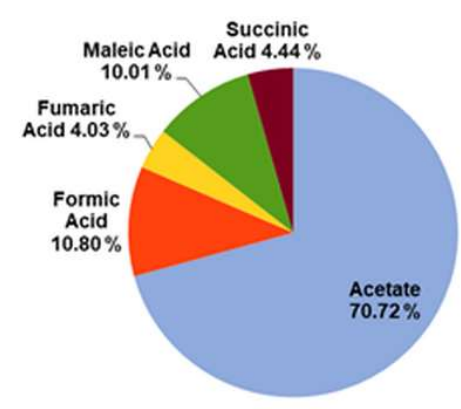

Organicacids

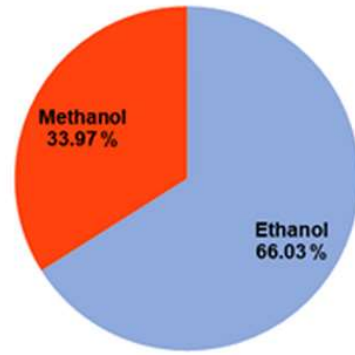

Alcohols

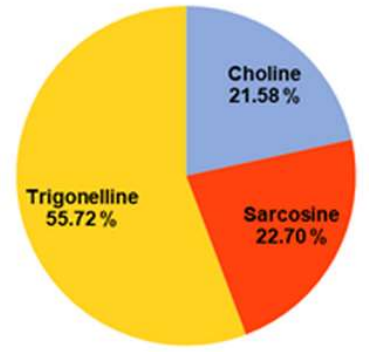

Osmolytes

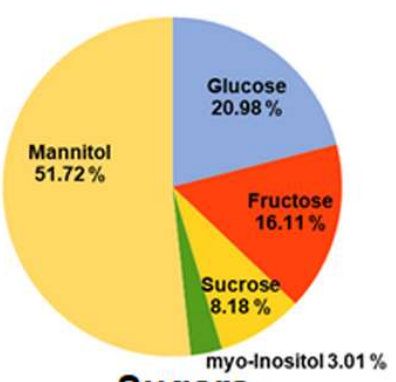

Sugars
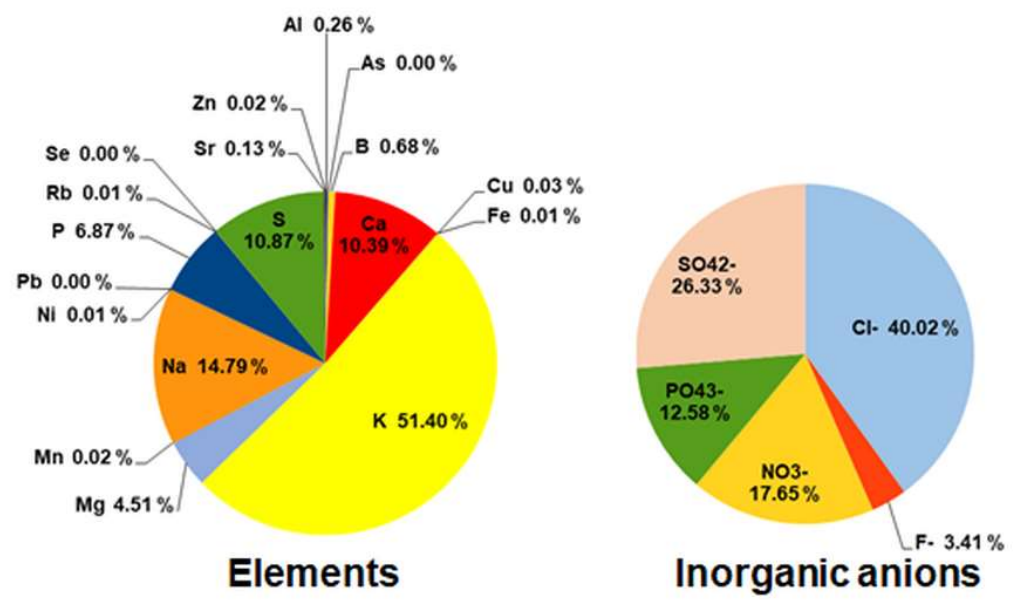

Figure 1. Percentage composition of the different organic groups, amino acids, organic acids, alcohols, sugars, osmolytes mineral elements and inorganic ions detected in olive xylem sap. 
Table 1. Mean content $(\mu \mathrm{M})$ and range of the main groups of metabolites identified in xylem sap from plantlets and adult olive trees of 'Picual' and 'Arbequina' genotypes and results of ANOVA analysis to determine the effects of plant age and genotype. For each treatment mean values and standard derivation are shown. Detection of each compound in the total samples tested is displayed in brackets.

\begin{tabular}{|c|c|c|c|c|c|c|c|c|}
\hline \multirow{2}{*}{ Metabolite } & \multirow{2}{*}{$\min -\max$} & \multicolumn{2}{|c|}{ Adult trees } & \multicolumn{2}{|c|}{ Plantlets } & \multicolumn{3}{|c|}{ ANOVA } \\
\hline & & Arbequina & Picual & Arbequina & Picual & Age (A) & Genotype (G) & $A \times G$ \\
\hline \multicolumn{9}{|l|}{ Organic Acids } \\
\hline Acetate & $97.9-264.6$ & $134.93 \pm 14.05(4 / 4)$ & $127.28 \pm 14.29(4 / 4)$ & $137.20 \pm 30.15(4 / 4)$ & $142.73 \pm 81.42(4 / 4)$ & 0.925 & 0.715 & 0.951 \\
\hline Formic Acid & $16.0-36.0$ & $22.43 \pm 5.39(4 / 4)$ & $16.98 \pm 1.62(4 / 4)$ & $24.70 \pm 9.49(4 / 4)$ & $18.73 \pm 1.54(4 / 4)$ & 0.509 & 0.065 & 0.883 \\
\hline Fumaric Acid & $1.6-17.4$ & $5.70 \pm 4.30(4 / 4)$ & $11.25 \pm 4.95(4 / 4)$ & $7.68 \pm 1.64(4 / 4)$ & $6.25 \pm 2.23(4 / 4)$ & 0.991 & 0.270 & 0.065 \\
\hline Maleic Acid & $9.8-29.4$ & $26.30 \pm 3.80(4 / 4)$ & $15.40 \pm 2.77(4 / 4)$ & $16.93 \pm 8.62(4 / 4)$ & $18.20 \pm 5.41(4 / 4)$ & 0.229 & 0.195 & 0.042 \\
\hline Succinic Acid & $1.6-29.5$ & $6.98 \pm 5.00(4 / 4)$ & $10.83 \pm 6.14(4 / 4)$ & $6.18 \pm 3.47(4 / 4)$ & $10.08 \pm 13.17(4 / 4)$ & 0.446 & 0.576 & 0.551 \\
\hline \multicolumn{9}{|l|}{ Aminoacids } \\
\hline Alanine & $2.7-11.5$ & $4.93 \pm 1.12(4 / 4)$ & $4.35 \pm 0.94(4 / 4)$ & $7.53 \pm 3.43(3 / 4)$ & $5.75 \pm 2.60(4 / 4)$ & 0.873 & 0.918 & 0.607 \\
\hline Arginine & $16.1-115.7$ & $106.40 \pm 0.00(1 / 4)$ & $30.67 \pm 26.71(3 / 4)$ & $25.00 \pm 0.00(1 / 4)$ & $69.80 \pm 64.91(2 / 4)$ & 0.712 & 0.262 & 0.982 \\
\hline Asparagine & $23.6-36.9$ & $\mathrm{nd}^{*}(0 / 4)$ & $32.17 \pm 5.39(3 / 4)$ & $36.20 \pm 0.00(1 / 4)$ & $28.85 \pm 7.42(2 / 4)$ & 0.987 & 0.054 & 0.272 \\
\hline Aspartate & $14.7-137.9$ & $34.90 \pm 0.00(1 / 4)$ & $48.07 \pm 54.61(3 / 4)$ & $23.50 \pm 7.35(2 / 4)$ & $53.05 \pm 57.33(4 / 4)$ & 0.345 & 0.050 & 0.833 \\
\hline GABA & $4.4-24.9$ & $8.00 \pm 5.09(2 / 4)$ & $18.70 \pm 7.49(2 / 4)$ & nd $(0 / 4)$ & $24.90 \pm 0.00(1 / 4)$ & 0.239 & 0.354 & 0.798 \\
\hline Glutamate & $4.5-856.1$ & $21.10 \pm 10.15(3 / 4)$ & $84.75 \pm 71.41(4 / 4)$ & $36.83 \pm 26.74(3 / 4)$ & $224.63 \pm 421.06(4 / 4)$ & 0.858 & 0.115 & 0.563 \\
\hline Glutamine & $12.7-2482.1$ & $142.55 \pm 90.44(4 / 4)$ & $63.33 \pm 45.89(4 / 4)$ & $510.57 \pm 474.87(3 / 4)$ & $672.90 \pm 1208.3(4 / 4)$ & 0.990 & 0.981 & 0.513 \\
\hline Isoleucine & $2.4-9.2$ & $3.43 \pm 1.03(4 / 4)$ & $5.03 \pm 2.88(4 / 4)$ & $4.07 \pm 1.81(3 / 4)$ & $4.47 \pm 2.54(3 / 4)$ & 0.326 & 0.585 & 0.683 \\
\hline Leucine & $1.4-6.3$ & $3.15 \pm 2.26(4 / 4)$ & $3.20 \pm 1.06(4 / 4)$ & $2.37 \pm 0.85(3 / 4)$ & $3.63 \pm 2.19(3 / 4)$ & 0.339 & 0.483 & 0.865 \\
\hline Methionine & $3.7-17.8$ & $7.05 \pm 4.73(2 / 4)$ & $12.85 \pm 1.06(2 / 4)$ & $13.70 \pm 5.79(2 / 4)$ & $7.15 \pm 0.21(2 / 4)$ & 0.953 & 0.964 & 0.625 \\
\hline Phenylalanine & $3.9-7.8$ & nd $(0 / 4)$ & $5.55 \pm 1.65(4 / 4)$ & $7.37+ \pm 0.23(3 / 4)$ & $5.30 \pm 1.69(2 / 4)$ & 0.388 & 0.182 & 0.006 \\
\hline Proline & $6.3-402.1$ & $12.00 \pm 0.00(1 / 4)$ & $53.30 \pm 15.27(2 / 4)$ & $26.25 \pm 70.63(2 / 4)$ & $140.10 \pm 226.90(3 / 4)$ & 0.456 & 0.292 & 0.859 \\
\hline Threonine & $5.3-186.1$ & $15.55 \pm 3.15(4 / 4)$ & $43.68 \pm 22.58(4 / 4)$ & $90.43 \pm 78.78(4 / 4)$ & $41.58 \pm 27.60(4 / 4)$ & 0.304 & 0.771 & 0.125 \\
\hline Tyrosine & $4.5-17.7$ & $8.97 \pm 0.40(3 / 4)$ & $7.65 \pm 2.81(4 / 4)$ & $12.83 \pm 3.40(4 / 4)$ & $10.95 \pm 5.20(4 / 4)$ & 0.090 & 0.868 & 0.403 \\
\hline Valine & $2.5-16.4$ & $8.73 \pm 6.53(4 / 4)$ & $5.98 \pm 1.54(4 / 4)$ & $6.10 \pm 1.94(4 / 4)$ & $6.08 \pm 3.57(4 / 4)$ & 0.675 & 0.653 & 0.952 \\
\hline \multicolumn{9}{|l|}{ Sugars } \\
\hline Glucose & $45.2-752.9$ & $333.43 \pm 162.12(4 / 4)$ & $443.83 \pm 216.31(4 / 4)$ & $145.13 \pm 77.58(4 / 4)$ & $216.13 \pm 132.94(4 / 4)$ & 0.029 & 0.378 & 0.918 \\
\hline Fructose & $39.2-634.6$ & $222.75 \pm 130.41(4 / 4)$ & $387.38 \pm 187.14(4 / 4)$ & $110.78 \pm 129.78(4 / 4)$ & $153.50 \pm 141.01(4 / 4)$ & 0.037 & 0.170 & 0.773 \\
\hline Sucrose & $25.4-220.1$ & $145.35 \pm 45.20(4 / 4)$ & $157.15 \pm 46.49(4 / 4)$ & $89.18 \pm 32.03(4 / 4)$ & $52.45 \pm 28.95(4 / 4)$ & 0.001 & 0.219 & 0.113 \\
\hline myo-Inositol & $14.1-90.2$ & $42.53 \pm 2.68(3 / 4)$ & $53.60 \pm 35.38(4 / 4)$ & $32.88 \pm 11.15(4 / 4)$ & $44.53 \pm 20.85(4 / 4)$ & 0.576 & 0.278 & 0.537 \\
\hline Mannitol & $72.6-1334.0$ & $839.73 \pm 76.19(4 / 4)$ & $1032.9 \pm 202.75(4 / 4)$ & $370.70 \pm 256.06(4 / 4)$ & $564.03 \pm 251.7(4 / 4)$ & 0.010 & 0.204 & 0.513 \\
\hline \multicolumn{9}{|l|}{ Osmolytes } \\
\hline Choline & $2.1-7.2$ & $4.15 \pm 0.37(4 / 4)$ & $4.90 \pm 2.16(4 / 4)$ & $3.95 \pm 3.60(2 / 4)$ & $3.53 \pm 2.28(3 / 4)$ & 0.038 & 0.599 & 0.760 \\
\hline Sarcosine & $2.2-13.1$ & $3.20 \pm 1.11(3 / 4)$ & $7.03 \pm 4.85(4 / 4)$ & $3.20 \pm 2.26(2 / 4)$ & $4.20 \pm 2.25(3 / 4)$ & 0.167 & 0.095 & 0.566 \\
\hline Trigonelline & $5.4-22.8$ & $11.80 \pm 7.68(4 / 4)$ & $9.73 \pm 3.15(4 / 4)$ & $7.23 \pm 1.68(4 / 4)$ & $8.50 \pm 0.82(4 / 4)$ & 0.231 & 0.817 & 0.474 \\
\hline \multicolumn{9}{|l|}{ Alcohols } \\
\hline Ethanol & $29.0-606.7$ & $43.43 \pm 6.42(4 / 4)$ & $144.50 \pm 161.52(4 / 4)$ & $409.45 \pm 162.01(4 / 4)$ & $163.55 \pm 142.90(4 / 4)$ & 0.008 & 0.609 & 0.018 \\
\hline Methanol & $35-276.4$ & $54.88 \pm 13.32(4 / 4)$ & $81.10 \pm 64.90(4 / 4)$ & $147.53 \pm 34.86(4 / 4)$ & $107.93 \pm 112.69(4 / 4)$ & 0.071 & 0.492 & 0.180 \\
\hline
\end{tabular}

$\left.{ }^{*}\right) \mathrm{nd}=$ not detected. 
Table 2. Mean content $(\mu \mathrm{M})$ and range of the main groups of elements and inorganic ions present in xylem sap from plantlets and adult olive trees of 'Picual' and 'Arbequina' genotypes and results of ANOVA analysis to determine the effects of plant age and genotype. For each treatment mean values and standard derivation are shown. Detection of each compound in the total samples tested is displayed in brackets.

\begin{tabular}{|c|c|c|c|c|c|c|c|c|}
\hline \multirow{2}{*}{ Compound } & \multirow{2}{*}{$\min -\max$} & \multicolumn{2}{|c|}{ Adult trees } & \multicolumn{2}{|c|}{ Plantlets } & \multicolumn{3}{|c|}{ ANOVA } \\
\hline & & Arbequina & Picual & Arbequina & Picual & Age (A) & Genotype (G) & $A \times G$ \\
\hline \multicolumn{9}{|l|}{ Element } \\
\hline $\mathrm{Al}$ & $5.4-41.4$ & $9.63 \pm 5.94(2 / 4)$ & $33.22 \pm 11.61(2 / 4)$ & $13.05 \pm 3.82(2 / 4)$ & $12.38 \pm 8.77(3 / 4)$ & 0.825 & 0.517 & 0.968 \\
\hline As & $0.1-0.5$ & $0.21 \pm 0.08(2 / 4)$ & nd $(0 / 4)$ & $0.41 \pm 0.00(1 / 4)$ & $0.05 \pm 0.00(1 / 4)$ & 0.373 & 0.538 & 0.536 \\
\hline B & $1.4-67.9$ & $49.41 \pm 15.68(4 / 4)$ & $28.19 \pm 10.03(4 / 4)$ & $12.78 \pm 7.37(4 / 4)$ & $10.32 \pm 7.78(3 / 4)$ & 0.002 & 0.089 & 0.630 \\
\hline $\mathrm{Ca}$ & $104.0-1208.0$ & $465.31 \pm 42.70(4 / 4)$ & $372.00 \pm 55.43(4 / 4)$ & $222.61 \pm 216.07(4 / 4)$ & $452.08 \pm 517.03(4 / 4)$ & 0.086 & 0.694 & 0.306 \\
\hline $\mathrm{Cu}$ & $0.3-1.6$ & $1.20 \pm 0.35(4 / 4)$ & $0.91 \pm 0.09(4 / 4)$ & $1.26 \pm 0.63(3 / 4)$ & $0.70 \pm 0.28(4 / 4)$ & 0.195 & 0.544 & 0.807 \\
\hline $\mathrm{Fe}$ & $0.3-1.2$ & $1.03 \pm 0.21(4 / 4)$ & $0.37 \pm 0.02(3 / 4)$ & $0.47 \pm 0.00(1 / 4)$ & $0.58 \pm 0.00(1 / 4)$ & 0.007 & 0.022 & 0.044 \\
\hline K & $1246.6-3571.2$ & $1743.8 \pm 160.4(4 / 4)$ & $1808.8 \pm 320.31(4 / 4)$ & $1556.3 \pm 277.21(4 / 4)$ & $2371.4 \pm 1056.8(4 / 4)$ & 0.765 & 0.177 & 0.244 \\
\hline $\mathrm{Mg}$ & $50.4-879.4$ & $90.00 \pm 9.33(4 / 4)$ & $92.84 \pm 16.94(4 / 4)$ & $156.56 \pm 173.11(4 / 4)$ & $316.95 \pm 388.10(4 / 4)$ & 0.347 & 0.570 & 0.607 \\
\hline Mn & $0.4-4.3$ & $0.89 \pm 0.05(4 / 4)$ & $0.46 \pm 0.12(4 / 4)$ & $1.53 \pm 0.00(1 / 4)$ & $4.33 \pm 0.00(1 / 4)$ & 0.435 & 0.991 & 0.175 \\
\hline $\mathrm{Na}$ & $156.5-1281.1$ & $410.28 \pm 43.45(4 / 4)$ & $709.86 \pm 22.76(4 / 4)$ & $365.80 \pm 178.67(4 / 4)$ & $666.55 \pm 433.10(4 / 4)$ & 0.332 & 0.024 & 0.997 \\
\hline $\mathrm{Ni}$ & $0.2-0.7$ & $n d^{*}(0 / 4)$ & $0.33 \pm 0.00(1 / 4)$ & $0.32 \pm 0.00(1 / 4)$ & $0.50 \pm 0.40(2 / 4)$ & 0.538 & 0.504 & 0.991 \\
\hline $\mathrm{P}$ & $34.7-556.0$ & $360.25 \pm 162.99(4 / 4)$ & $198.94 \pm 25.91(4 / 4)$ & $204.80 \pm 155.74(4 / 4)$ & $235.52 \pm 66.57(4 / 4)$ & 0.652 & 0.805 & 0.153 \\
\hline $\mathrm{Pb}$ & $0.07-0.1$ & $0.07 \pm 0.00(1 / 4)$ & nd $(0 / 4)$ & nd $(0 / 4)$ & $0.10 \pm 0.00(1 / 4)$ & 0.298 & 0.889 & 0.144 \\
\hline $\mathrm{Rb}$ & $0.2-0.8$ & $0.39 \pm 0.01(4 / 4)$ & $0.35 \pm 0.08(3 / 4)$ & $0.62 \pm 0.20(4 / 4)$ & $0.59 \pm 0.14(4 / 4)$ & 0.006 & 0.266 & 0.357 \\
\hline$S$ & $48.6-2330.9$ & $249.43 \pm 45.61(4 / 4)$ & $194.87 \pm 18.93(4 / 4)$ & $341.73 \pm 367.40(4 / 4)$ & $796.26 \pm 1075.4(4 / 4)$ & 0.746 & 0.971 & 0.815 \\
\hline Se & $0.1-0.3$ & $0.13 \pm 0.00(1 / 4)$ & $0.30 \pm 0.00(1 / 4)$ & nd (0/4) & nd $(0 / 4)$ & 0.848 & 0.913 & 0.751 \\
\hline $\mathrm{Sr}$ & $0.3-10.3$ & $9.02 \pm 1.04(4 / 4)$ & $6.24 \pm 0.99(4 / 4)$ & $0.85 \pm 0.35(4 / 4)$ & $2.75 \pm 1.55(4 / 4)$ & $<0.001$ & 0.077 & 0.003 \\
\hline $\mathrm{Zn}$ & $0.3-1.3$ & $0.77 \pm 0.10(4 / 4)$ & $0.58 \pm 0.07(4 / 4)$ & $0.44 \pm 0.08(4 / 4)$ & $0.91 \pm 0.46(3 / 4)$ & 0.233 & 0.872 & 0.377 \\
\hline \multicolumn{9}{|c|}{ Inorganic Anions } \\
\hline $\mathrm{Cl}^{-}$ & $2098.9-3925.2$ & $2422.6 \pm 67.18(4 / 4)$ & $2545.2 \pm 219.52(4 / 4)$ & $2539.1 \pm 668.37(4 / 4)$ & $3048.1 \pm 593.46(4 / 4)$ & 0.236 & 0.151 & 0.918 \\
\hline $\mathrm{F}-$ & $121.2-295.4$ & $245.14 \pm 28.32(4 / 4)$ & $245.81 \pm 35.64(4 / 4)$ & $195.70 \pm 58.43(4 / 4)$ & $213.64 \pm 2.98(4 / 4)$ & 0.058 & 0.514 & 0.773 \\
\hline $\mathrm{NO}_{3-}^{-}$ & $762.8-2581.9$ & $941.12 \pm 77.57(4 / 4)$ & $787.04 \pm 30.56(4 / 4)$ & $1488.7 \pm 376.20(4 / 4)$ & $1438.2 \pm 822.63(4 / 4)$ & 0.009 & 0.327 & 0.113 \\
\hline $\mathrm{PO}_{4}^{3-}$ & $741.8-1038.7$ & $927.47 \pm 104.85(4 / 4)$ & $813.42 \pm 17.03(4 / 4)$ & $789.21 \pm 60.03(4 / 4)$ & $788.06 \pm 30.53(4 / 4)$ & 0.021 & 0.104 & 0.537 \\
\hline $\mathrm{SO}_{4}^{2-}$ & $1470.2-3005.4$ & $1657.8 \pm 28.86(4 / 4)$ & $1620.5 \pm 14.80(4 / 4)$ & $1694.7 \pm 218.43(4 / 4)$ & $1970.4 \pm 722.29(4 / 4)$ & 0.370 & 0.629 & 0.513 \\
\hline
\end{tabular}

$\left({ }^{*}\right) \mathrm{nd}=$ not detected. 
On the other hand, ICP-OES allowed the detection of 18 elements and five inorganic anions (Table 2). All inorganic anions were detected in all samples studied, while more variable was the detection of other elements, such as Fe and Mn which displayed a higher frequency of detection in adult trees than in plantlets (Table 2).

In general, olive xylem sap metabolites included a higher relative percentage of sugars $(54.35 \%)$, followed by alcohols $(28.85 \%)$, amino acids $(8.01 \%)$, organic acids $(7.68 \%)$ and osmolytes (1.12\%) (Figure 1). Among the five organic acids detected acetate and formic acid exhibited the highest proportion with $70.72 \%$ and $10.80 \%$ of the total, respectively. Similarly, the amino acids glutamine and glutamate were the most abundant in xylem sap, comprising more than $65 \%$ of total amino acids $(52.59 \%$ and $14.72 \%$, respectively). Furthermore, mannitol $(51.72 \%)$ and glucose $(20.98 \%)$ showed the greatest levels within all sugar compounds. On the other hand, the alcohol detected at higher proportion was ethanol $(66.03 \%)$ whereas the prevalent osmolyte was trigonelline (55.72\%) (Figure 1). Ionome analysis revealed that $\mathrm{K}(51.40 \%)$ and $\mathrm{Na}(14.79 \%)$ were the most abundant mineral macroelements followed by S, Ca and P $(10.87 \%, 10.39 \%$ and $6.87 \%$, respectively). On the other hand, $\mathrm{Cl}^{-}(40.02 \%)$ and $\mathrm{SO}_{4}{ }^{2-}(26.33 \%)$ were positioned as the prevalent anions found in olive xylem sap (Figure 1C). Other microelements detected included $\mathrm{B}, \mathrm{Cu}, \mathrm{Zn}$ and $\mathrm{Mn}$ with abundances ranging from $0.68 \%$ to $0.02 \%$, whereas $\mathrm{Ni}$, $\mathrm{Fe}$ and $\mathrm{Rb}$ were detected at $<0.01 \%$ of the total mineral elements.

\subsection{Effect of olive plant age and genotype in xylem sap composition}

Analysis of variance (ANOVA) indicated the existence of significant differences on the levels of some metabolites according to the plant age including the sugars glucose, fructose, sucrose and mannitol and the osmolite choline that showed significant $(P<0.037)$ higher values in adult trees as compared to plantlets for both olive genotypes (Table 1). Aspartate content showed significant higher values $(P=0.0496)$ in 'Picual' plants than in 'Arbequina' plants irrespective of plant age. Phenylalanine was not detected on adult trees of 'Arbequina' and showed similar values for the other three experimental combinations. Additionally, ethanol content was significantly higher $(P<0.037)$ in plantlets as compared to adult trees, but only in cv. Arbequina.

Concerning mineral elements and inorganic ions, the concentration of $\mathrm{B}$ and $\mathrm{PO}_{4}{ }^{3}$ were significantly higher $(P<0.021)$ in adult trees than in plantlets, whereas $\mathrm{NO}_{3}-$ and $\mathrm{Rb}$ content showed the opposite behavior (Table 2). On the other hand, Na content was significantly $(P=0.024)$ higher in 'Picual' than in 'Arbequina' plants for both plant ages and Fe showed the opposite behavior but only for adult trees (contrast $P=0.086$ ) (Table 2). Finally, Sr showed significant $(P<0.033)$ higher values for adult plants as compared to plantlets, except for 'Picual' where no differences existed between the two plant ages $(P=0.635)$.

Hierarchical clustering analysis using all chemical compounds identified by metabolomic and ionomic analysis separated xylem sap composition according to the olive plant age in first place, with a minor role of the olive cultivar (Figure 2). Similarly, PLS-DA analysis of all metabolites, mineral elements and inorganic ions were clearly distinct for xylem sap according to the plant age, and then within them there was a trend to group the xylem samples according to the olive genotype ('Arbequina' and 'Picual'), with this effect being more clear for adult trees (Figure 3A). PLS-DA ranked the compounds using the variable importance in projection (VIP) scores at $P=0.05$, and showed that Sr, B, Fructose, Mannitol, Fe, sucrose and glucose had the highest VIP scores, showing values higher for adult trees as compared to plantlets, with ethanol showing the opposite trend (Figure 3A). Additionally, for the PLS-DA models clearly discriminated 'Arbequina' and 'Picual' olive genotypes when separate analyses were performed for each plant age. Asparagine, glutamate, phenylalanine and aspartate were the compounds that showed higher VIP score values and reached lower concentrations in 'Arbequina' than in 'Picual' for adult trees. On the other hand, aspartate, ethanol, arginine and Sr were the most contributory VIP variables in the discrimination of both genotypes in the PLS-DA 
model for plantlets. Thus, all those compounds, with the only exception of ethanol, showed lower levels in 'Arbequina' than in 'Picual' seedlings (Figure 3B).

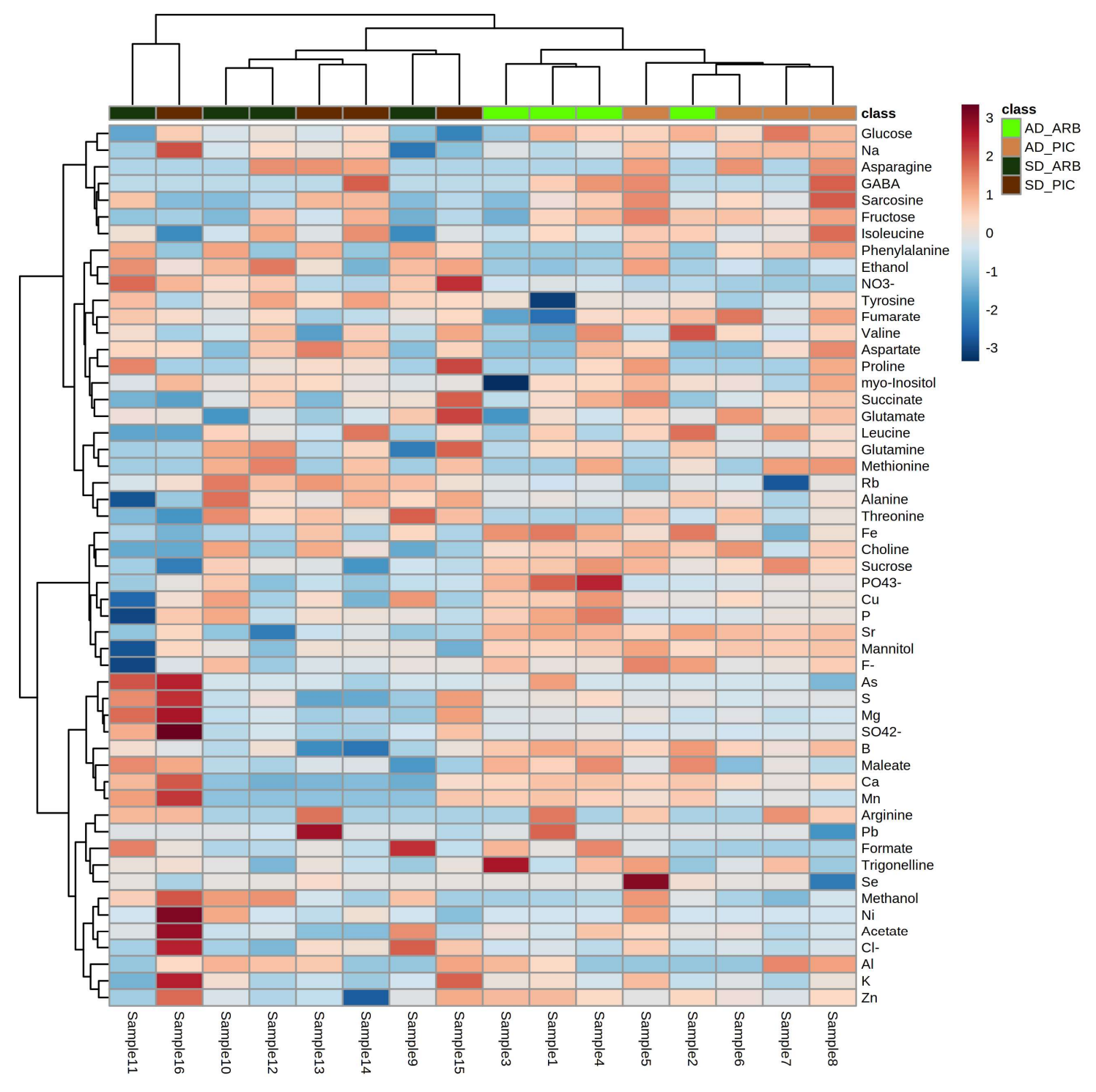

Figure 2. Hierarchical clustering and heatmap of metabolomic and ionomic profile of olive xylem sap of adult trees (AD) and plantlets (SD) of olive cultivars 'Picual' and 'Arbequina'. 
A

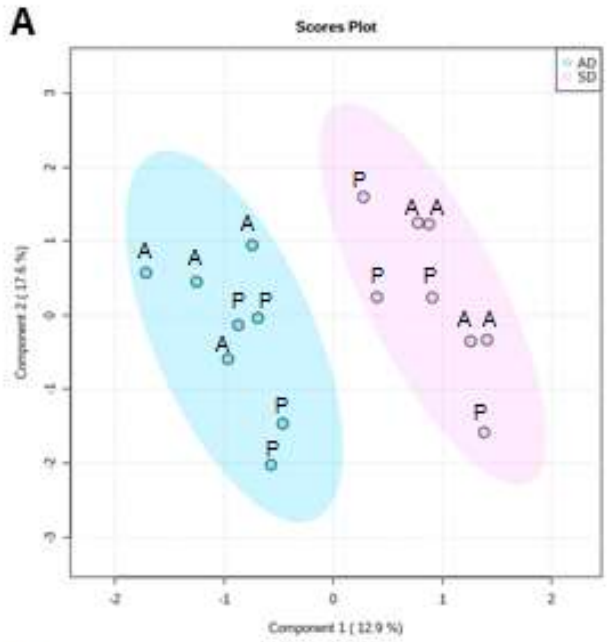

B

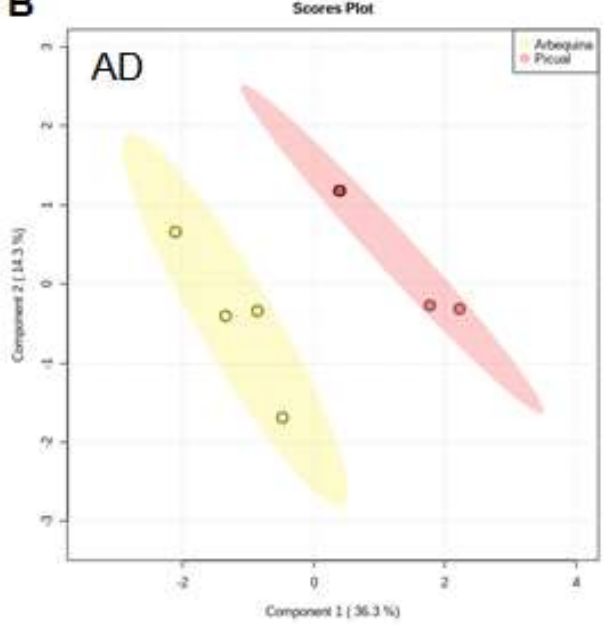

Scoes Plot

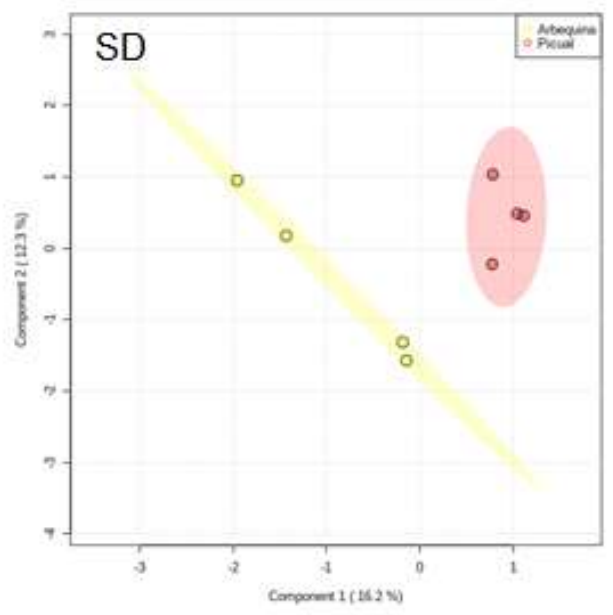

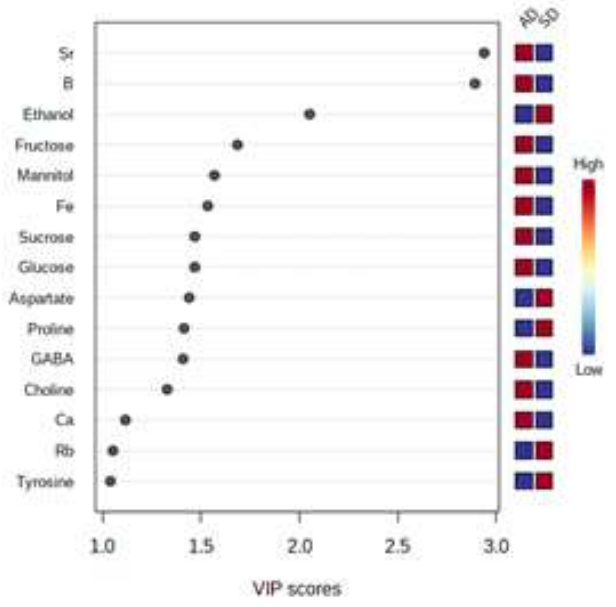
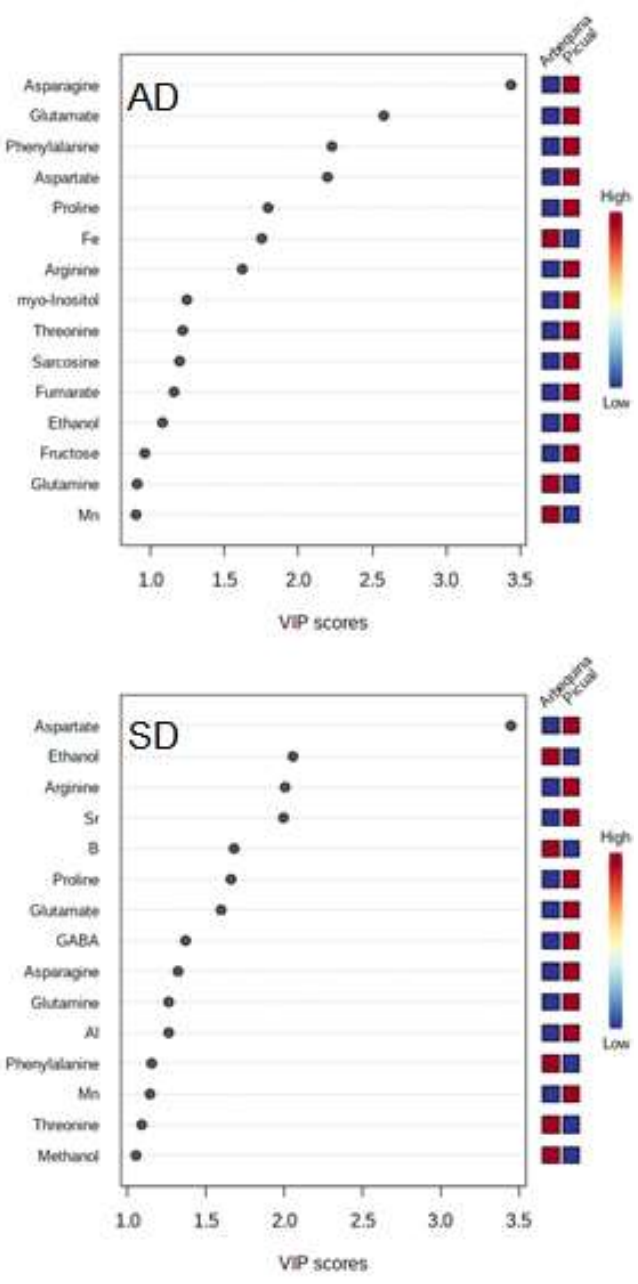

Figure 3. Partial least squares discriminant (PLS-DA) 2D score plot and loading importance in projection (VIP scores) in the first PLS-DA component of metabolomic and ionomic profile of olive xylem sap of adult trees (AD) and plantlets (SD) of olive cultivars 'Picual' and 'Arbequina'. (A) Combined analysis of all olive cultivars and plant age combinations. (B) Separate analysis by olive plant age. 


\section{Discussion}

The results of this study reveal for the first time the effect of plant age and olive genotype on the differentiation of the chemical composition of olive xylem sap. These new insights of the metabolomics and ionomic profile of olive xylem sap provide new information for the characterization of the living environment for xylem-inhabiting olive endophytes which may result in a better understanding of the nutritional requirements for growth of those microorganisms. Indeed, knowing the nutritional requirements of the xylem plant-associated microorganisms will enable to design more specific culture media for its in vitro cultivation and isolation and to understand some factors related to the biology and pathogenicity of emerging xylem-inhabiting pathogens, such as $V$. dahliae and $X$. fastidiosa that represent the major threats for olive growth and productivity worldwide.

Our results showed that olive xylem sap contains a wide variety of chemical compounds. Thus, we found a high level of sugars, which were the main metabolites present in olive xylem sap, followed by alcohols, amino acids and organic acids. In fact, mean values displayed mannitol, ethanol, glutamine and acetate as the principal compounds within each chemical group. These results are in line with the findings of several authors where mannitol was abundant in sap from maples [39] or the glutamine was found the main amino acid in tomato, maize and grapevine $[16,28,40]$. In addition, the role of these compounds in the plant kingdom have been widely reported. Thus, mannitol is known as an osmoregulator being synthesized by plants in response to dehydration conditions [41] and has a remarkable role in protecting plant cells against damage by reactive oxygen species (ROS) [42]. Otherwise, several works have studied the role of glutamine amino acid in the activation of defense responses of the plant against pathogens where the deficit of glutamine is linked to the inhibition of glutamine synthetase complex activating plant defense genes [43,44]; or the antibacterial activity of acetate that supports flavonoid and lipid biosynthesis $[45,46]$. In relation to ions, $\mathrm{K}$ and $\mathrm{Cl}^{-}$were the element and inorganic anion more abundant, respectively. High levels of $\mathrm{K}$ were reported in grapevines [47] whose availability is determinant for a properly plant growth [48].

Although, several authors have identified the chemical composition of xylem sap in different crops [26-30] overcoming the technical difficulties and labor-intensive task of sap extraction from xylem tissues avoiding cytosolic contamination has been a challenge. This explains why a considerable gap of knowledge on the effect of plant age and genotype on the chemical composition of the xylem sap exists. Thus, the influence of plant age and genotype in the chemical composition of xylem sap have been overlooked, only few studies have reported this interaction in leaves and roots. Nevertheless, some metabolomic studies have determined the existence of some differentiation of chemical compound dynamics during different plant growth stages in potato [49], soybeans [50], ginseng [51] and others herbaceous plants $[52,53]$ that may have contributed to different biological activity of the plant, such as flowering period, or might be the result of variations on soil properties or environmental conditions [49,50]. Other studies have determined the effect of plant genotype on sap composition including birch trees [54], mango [55], maize [56] and grapevines [57]. Although there is no systematic analysis of how genotype influences plant metabolome and ionome, some predictions address these differences depending on the organism considered, the analytical technique used, the tissue sampled and, most significantly, the interaction of the genotype with the environment due to the compensatory role of metabolites to maintain metabolic homeostasis through the genetic adaptation to environmental stress [58]. Hence, this work aimed to remediate the lack of information in olive concerning its xylem sap composition to generate new insights that may be useful in future research by different disciplines including physiology, microbial ecology and plant pathology, among others. Our results 
suggested that the metabolome and ionome profile of olive xylem sap varied mainly according to host plant age with the olive genotype playing a secondary role. These differential results may be due not only to the juvenile stage of the plantlets, but likely to the different fertilization regimens that each type of plant received during its entire life.

For olive in particular, some works have addressed the fruit metabolome from 'Leccino' and 'Frantoio' cultivars [59] or the variation of metabolites composition among different olive tissues including leaves and fruits [60]. However, most of the research has focused on the olive oil metabolome [e.g., 61-63]. To the best of our knowledge, only one work has studied the xylem sap composition based on the use of liquid chromatography (UHPLC) coupled to a hybrid quadrupoletime-of-flight mass spectrometer (QTOF-MS) [30]. Our results were obtained using NMR and ICP-OES, that although is less sensitive than mass spectrometry, have been shown to provide powerful insights for highthroughput metabolomics application detecting a wide range of metabolites in an quantitative manner [64,65]. QTOF-MS provided to Sofo et al., [30] the wide discrimination of xylem sap secondary metabolism but only few primary metabolites including some amino acids (leucine, isoleucine, tyrosine, glutamate and arginine) and organic acids (fumaric and maleic acids) were detected in contrast to our results that involved the discrimination of the primary metabolism of xylem sap supplying five organic acids, 15 amino acids and five sugars, among other molecules. Furthermore, as a difference our work also provided information on the main mineral elements an inorganic anions present in the olive xylem sap.

In this study, the differences found on xylem sap composition between both olive cultivars were of particular interest, especially those found in adult trees were the effect of the genotype was more noticeable than in young plantlets, even though both genotypes have received same agronomic practices and grew in the same field for more than 10 years. This differential composition of xylem sap deserves further research by including additional olive genotypes, since they differ significantly in their resistance response to Verticillium wilt caused by $V$. dahliae $[66,67]$ and $X$. fastidiosa $[6,68,69]$. Interestingly, several authors have studied the effect of both vascular pathogens, $X$. fastidiosa $[68,70-72]$ and $V$. dahliae $[1,73]$ in the metabolomics and ionomic profile of olive trees where the identification of specific chemical compounds in stems, leaves, and fruits have been referred to as potentially being involved in the defense mechanisms of the host plant against these pathogens.

This present study is the first to date that shows the use of a metabolomic and ionomic approach for detection of specific differences in xylem sap composition upon contrasting stages of plant age and olive genotypes. Being aware of our limitations due to few samples analyzed and the exploration of only two olive genotypes, we observed a major influence of olive plant age in xylem sap content, with a clear differentiation between the plantlets from the adult trees while the effect of the genotype was more evident on adult trees. These results have provided new knowledge on the chemical composition of olive xylem sap that will be very useful for the characterization of the nutritional requirements of olive xylem-inhabiting microorganisms. These results will also help to design more specific culture media facilitating the isolation and in vitro growth of the xylem-inhabiting olive microbiome [32] which can serve as potential biological control agents against vascular pathogens in olive.

Author Contributions: MA-M and BL: conceived research and wrote the manuscript; MA-M, JAN$\mathrm{C}$ and BBL: performed statistical analyses; $\mathrm{MA}-\mathrm{M}, \mathrm{CH}$ and $\mathrm{MM}-\mathrm{B}$ : prepared materials and equipment and performed the experiments. LF and JAN-C: contributed to reviewing the manuscript and interpreting results. All authors viewed and approved the manuscript. 
Funding: This research was funded by projects AGL2016-75606-R (Programa Estatal de I+D Orientado a los Retos de la Sociedad from the Spanish Government and the Spanish State Research Agency and FEDER-EU) and XF-ACTORS (Xylella fastidiosa Active Containment Through a Multidisciplinary-Oriented Research Strategy; grant 727987 from the European Union's Horizon 2020 Framework Research Programme). MA-M is a recipient of a research fellowship BES-2017082361 from the Spanish Ministry of Economy and Competitiveness.

Conflicts of Interest: The authors declare no conflict of interest. The funders had no role in the design of the study; in the collection, analyses, or interpretation of data; in the writing of the manuscript, or in the decision to publish the results.

Institutional Review Board Statement: Not applicable.

Informed Consent Statement: Not applicable.

Data Availability Statement: Data sharing is not applicable to this article.

\section{References}

1. Landa, B.B.; Pérez, A.G.; Luaces, P.; Montes-Borrego, M.; Navas-Cortés, J.A.; Sanz, C. Insights into the effect of Verticillium dahliae defoliating-pathotype infection on the content of phenolic and volatile compounds related to the sensory properties of virgin olive oil. Front. Plant Sci. 2019, 10, 232.

2. Allen, H.D.; Randall, R.E.; Amable, G.S.; Devereux, B.J. The impact of changing olive cultivation practices on the ground flora of olive groves in the Messara and Psiloritis regions, Crete, Greece. L. Degrad. Dev. 2006, 17, 249-273, doi:10.1002/ldr.716.

3. Gómez, A.J.; Infante-Amate, J.; De Molina, G.M.; Vanwalleghem, T.; Taguas, V.E.; Lorite, I. Olive Cultivation, its Impact on Soil Erosion and its Progression into Yield Impacts in Southern Spain in the Past as a Key to a Future of Increasing Climate Uncertainty. Agric. 2014, 4.

4. Tscheulin, T.; Neokosmidis, L.; Petanidou, T.; Settele, J. Influence of landscape context on the abundance and diversity of bees in Mediterranean olive groves. Bull. Entomol. Res. 2011, 101, 557-564, doi:10.1017/S0007485311000149.

5. Jiménez-Díaz, R.M.; Cirulli, M.; Bubici, G.; del Mar Jiménez-Gasco, M.; Antoniou, P.P.; Tjamos, E.C. Verticillium Wilt, a major threat to olive production: current status and future prospects for its management. Plant Dis. 2011, 96, 304-329, doi:10.1094/PDIS06-11-0496.

6. Saponari, M.; Giampetruzzi, A.; Loconsole, G.; Boscia, D.; Saldarelli, P. Xylella fastidiosa in Olive in Apulia: Where We Stand. Phytopathology 2018, 109, 175-186, doi:10.1094/PHYTO-08-18-0319-FI.

7. White, P.J. Chapter 3 - Long-distance Transport in the Xylem and Phloem. In; Marschner, P.B.T.-M.M.N. of H.P. (Third E., Ed.; Academic Press: San Diego, 2012; pp. 49-70 ISBN 978-0-12-384905-2.

8. De Boer, A.H.; Volkov, V. Logistics of water and salt transport through the plant: structure and functioning of the xylem. Plant. Cell Environ. 2003, 26, 87-101, doi:10.1046/j.1365-3040.2003.00930.x.

9. Schurr, U. Xylem sap sampling-new approaches to an old topic. Trends Plant Sci. 1998, 3, 293-298, doi:https://doi.org/10.1016/S1360-1385(98)01275-8.

10. Horsfield, D. Relationships between feeding of Philaenus spumarius (L.) and the amino acid concentration in the xylem sap. Ecol. Entomol. 1977, 2, 259-266, doi:10.1111/j.1365-2311.1977.tb00889.x.

11. Sauter, J.J. Seasonal Variation of Amino Acids and Amides in the Xylem Sap of Salix. Zeitschrift für Pflanzenphysiologie 1981, 101, 399-411, doi:https://doi.org/10.1016/S0044-328X(81)80079-7.

12. Schurr, U.; Schulze, E.-D. The concentration of xylem sap constituents in root exudate, and in sap from intact, transpiring castor bean plants (Ricinus communis L.). Plant. Cell Environ. 1995, 18, 409-420, doi:10.1111/j.1365-3040.1995.tb00375.x. 
13. Tatár, E.; Mihucz, V.G.; Varga, A.; Záray, G.; Fodor, F. Determination of Organic Acids in Xylem Sap of Cucumber: Effect of Lead Contamination. Microchem. J. 1998, 58, 306-314, doi:https://doi.org/10.1006/mchj.1997.1559.

14. Fernández-García, N.; Hernández, M.; Casado-Vela, J.; Bru, R.; Elortza, F.; Hedden, P.; Olmos, E. Changes to the proteome and targeted metabolites of xylem sap in Brassica oleracea in response to salt stress. Plant. Cell Environ. 2011, 34, 821-836, doi:10.1111/j.1365-3040.2011.02285.x.

15. Krishnan, H.B.; Natarajan, S.S.; Bennett, J.O.; Sicher, R.C. Protein and metabolite composition of xylem sap from field-grown soybeans (Glycine max). Planta 2011, 233, 921-931, doi:10.1007/s00425-011-1352-9.

16. Alvarez, S.; Marsh, E.L.; Schroeder, S.G.; Schachtman, D.P. Metabolomic and proteomic changes in the xylem sap of maize under drought. Plant. Cell Environ. 2008, 31, 325-340, doi:10.1111/j.1365-3040.2007.01770.x.

17. Gollan, T.; Schurr, U.; Schulze, E.-D. Stomatal response to drying soil in relation to changes in the xylem sap composition of Helianthus annuus. I. The concentration of cations, anions, amino acids in, and pH of, the xylem sap. Plant. Cell Environ. 1992, 15, 551-559, doi:10.1111/j.1365-3040.1992.tb01488.x.

18. Ferguson, A.R. Xylem Sap from Actinidia chinensis: Apparent Differences in Sap Composition Arising from the Method of Collection. Ann. Bot. 1980, 46, 791-801.

19. Dambrine, E.; Martin, F.; Carisey, N.; Granier, A.; Hällgren, J.-E.; Bishop, K. Xylem sap composition: A tool for investigating mineral uptake and cycling in adult spruce. Plant Soil 1995, 168, 233-241, doi:10.1007/BF00029333.

20. Jones, O.P. Effects of Rootstocks and Interstocks on the Xylem Sap Composition in Apple Trees: Effects on Nitrogen, Phosphorus, and Potassium Content. Ann. Bot. 1971, 35, 825-836.

21. Subramanian, S.; Cho, U.-H.; Keyes, C.; Yu, O. Distinct changes in soybean xylem sap proteome in response to pathogenic and symbiotic microbe interactions. BMC Plant Biol. 2009, 9, 119, doi:10.1186/1471-2229-9-119.

22. Wallis, C. M., and Chen, J. 2012. Grapevine phenolic compounds in xylem sap and tissues are significantly altered during infection by Xylella fastidiosa. Phytopathology 102:816-826.

23. Thomas, R.J.; Feller, U.; Erismann, K.H. The effect of different inorganic nitrogen sources and plant age on the composition of bleeding sap of Phaseolus vulgaris. New Phytol. 1979, 82, 657-669, doi:10.1111/j.1469-8137.1979.tb01660.x.

24. Tromp, J. Seasonal Variations in the Composition of Xylem Sap of Apple with Respect to K, Ca, Mg, and N. Zeitschrift für Pflanzenphysiologie 1979, 94, 189-194, doi: 10.1016/S0044-328X(79)80157-9.

25. Ferguson, A.R.; Eiseman, J.A.; Leonard, J.A. Xylem Sap from Actinidia chinensis: seasonal Changes in Composition. Ann. Bot. $1983,51,823-833$.

26. Rennenberg, H.; Schupp, R.; Glavac, V.; Jochheim, H. Xylem sap composition of beech (Fagus sylvatica L.) trees: seasonal changes in the axial distribution of sulfur compounds. Tree Physiol. 1994, 14, 541-548.

27. Rellán-Álvarez, R.; El-Jendoubi, H.; Wohlgemuth, G.; Abadía, A.; Fiehn, O.; Abadía, J.; Alvarez-Fernández, A. Metabolite profile changes in xylem sap and leaf extracts of strategy I plants in response to iron deficiency and resupply. Front. Plant Sci. 2011, 2, 66, doi:10.3389/fpls.2011.00066.

28. Lima, M.R.M.; Machado, A.F.; Gubler, W.D. Metabolomic Study of Chardonnay Grapevines Double Stressed with EscaAssociated Fungi and Drought. Phytopathology 2017, 107, 669-680, doi:10.1094/PHYTO-11-16-0410-R.

29. Gallinger, J.; Gross, J. Unraveling the Host Plant Alternation of Cacopsylla pruni - Adults but Not Nymphs Can Survive on Conifers Due to Phloem/Xylem Composition. Front. Plant Sci. 2018, 9, 484, doi:10.3389/fpls.2018.00484.

30. Sofo, A.; Fausto, C.; Mininni, A.N.; Dichio, B.; Lucini, L. Soil management type differentially modulates the metabolomic profile of olive xylem sap. Plant Physiol. Biochem. 2019, 139, 707-714, doi:10.1016/j.plaphy.2019.04.036. 
31. Barranco, D. Varieties and rootstocks.; Barranco, D., Fernánndez-, Escobar, R., Rallo, L., Eds.; Olive Grow.; Pendle Hill, Australia: Junta de Andalucía/Mundi Prensa/RIRDC/AOA, 2010.

32. Anguita-Maeso, M., Olivares-García, C., Haro, C., Imperial, J., Navas-Cortés, J.A. and Landa, B.B. Culture-Dependent and Culture-Independent Characterization of the Olive Xylem Microbiota: Effect of Sap Extraction Methods. Front. Plant Sci. 2020, 10, 1708. doi: 10.3389/fpls.2019.01708

33. de la Rosa, G.; Peralta-Videa, J.R.; Montes, M.; Parsons, J.G.; Cano-Aguilera, I.; Gardea-Torresdey, J.L. Cadmium uptake and translocation in tumbleweed (Salsola kali), a potential Cd-hyperaccumulator desert plant species: ICP/OES and XAS studies. Chemosphere 2004, 55, 1159-1168, doi:10.1016/j.chemosphere.2004.01.028.

34. Akhtar, S.S.; Andersen, M.N.; Liu, F. Biochar Mitigates Salinity Stress in Potato. J. Agron. Crop Sci. 2015, 201, 368-378, doi:10.1111/jac.12132.

35. Fox, J., Weisberg, S. An R Companion to Applied Regression, Third edition. Sage, Thousand Oaks CA. 2019, https://socialsciences.mcmaster.ca/jfox/Books/Companion/.

36. Kassambara, A. rstatix: Pipe-Friendly Framework for Basic Statistical Tests. 2020. R Package Version 0.4.0. Available online at: https://cran.r-project.org/web/packages/rstatix/index.html.

37. Lee, L.C.; Liong, C.-Y.; Jemain, A.A. Partial least squares-discriminant analysis (PLS-DA) for classification of high-dimensional (HD) data: a review of contemporary practice strategies and knowledge gaps. Analyst 2018, 143, 3526-3539, doi:10.1039/C8AN00599K.

38. Chong, J.; Wishart, D.S.; Xia, J. Using MetaboAnalyst 4.0 for Comprehensive and Integrative Metabolomics Data Analysis. Curr. Protoc. Bioinforma. 2019, 68, e86, doi: 10.1002/cpbi.86.

39. Garcia, E.J.; McDowell, T.; Ketola, C.; Jennings, M.; Miller, J.D.; Renaud, J.B. Metabolomics reveals chemical changes in Acer saccharum sap over a maple syrup production season. PLoS One 2020, 15, e0235787.

40. Sung, J.; Sonn, Y.; Lee, Y.; Kang, S.; Ha, S.; Krishnan, H.B.; Oh, T.-K. Compositional changes of selected amino acids, organic acids, and soluble sugars in the xylem sap of N, P, or K-deficient tomato plants. J. Plant Nutr. Soil Sci. 2015, 178, 792-797, doi:10.1002/jpln.201500071.

41. Hare, P.D.; Cress, W.A.; Van Staden, J. Dissecting the roles of osmolyte accumulation during stress. Plant. Cell Environ. 1998, 21, 535-553, doi:10.1046/j.1365-3040.1998.00309.x.

42. Patel, T.K.; Williamson, J.D. Mannitol in Plants, Fungi, and Plant-Fungal Interactions. Trends Plant Sci. 2016, 21, 486-497, doi:10.1016/j.tplants.2016.01.006.

43. Huang, H.; Nguyen Thi Thu, T.; He, X.; Gravot, A.; Bernillon, S.; Ballini, E.; Morel, J.-B. Increase of Fungal Pathogenicity and Role of Plant Glutamine in Nitrogen-Induced Susceptibility (NIS) To Rice Blast. Front. Plant Sci. 2017, 8, 265, doi: 10.3389/fpls.2017.00265

44. Seabra, A.R.; Carvalho, H. Inhibition of glutamine synthetase leads to a fast transcriptional activation of defense responses in root nodules. Model Legum. Medicago truncatula 2020, 665-673, doi: 10.1002/9781119409144.ch82

45. Wei, J.; Wang, S.; Pei, D.; Qu, L.; Li, Y.; Chen, J.; Di, D.; Gao, K. Antibacterial Activity of Hydroxytyrosol Acetate from Olive Leaves (Olea Europaea L.). Nat. Prod. Res. 2018, 32, 1967-1970, doi:10.1080/14786419.2017.1356830.

46. Perez de Souza, L.; Garbowicz, K.; Brotman, Y.; Tohge, T.; Fernie, A.R. The Acetate Pathway Supports Flavonoid and Lipid Biosynthesis in Arabidopsis. Plant Physiol. 2020, 182, 857 LP - 869, doi:10.1104/pp.19.00683.

47. Prima-Putra, D.; Botton, B. Organic and inorganic compounds of xylem exudates from five woody plants at the stage of bud breaking. J. Plant Physiol. 1998, 153, 670-676, doi:10.1016/S0176-1617(98)80219-8. 
48. Xu, X.; Du, X.; Wang, F.; Sha, J.; Chen, Q.; Tian, G.; Zhu, Z.; Ge, S.; Jiang, Y. Effects of Potassium Levels on Plant Growth, Accumulation and Distribution of Carbon, and Nitrate Metabolism in Apple Dwarf Rootstock Seedlings. Front. Plant Sci. 2020, 11, 904, doi: 10.3389/fpls.2020.00904.

49. Puzanskiy, R.K.; Yemelyanov, V. V; Shavarda, A.L.; Gavrilenko, T.A.; Shishova, M.F. Age- and Organ-Specific Differences of Potato (Solanum phureja) Plants Metabolome. Russ. J. Plant Physiol. 2018, 65, 813-823, doi: 10.1134/S1021443718060122.

50. Yun, D.-Y.; Kang, Y.-G.; Kim, E.-H.; Kim, M.; Park, N.-H.; Choi, H.-T.; Go, G.H.; Lee, J.H.; Park, J.S.; Hong, Y.-S. Metabolomics approach for understanding geographical dependence of soybean leaf metabolome. Food Res. Int. 2018, 106, 842-852, doi: 10.1016/j.foodres.2018.01.061.

51. Kim, Y.-J.; Joo, S.C.; Shi, J.; Hu, C.; Quan, S.; Hu, J.; Sukweenadhi, J.; Mohanan, P.; Yang, D.-C.; Zhang, D. Metabolic dynamics and physiological adaptation of Panax ginseng during development. Plant Cell Rep. 2018, 37, 393-410, doi: 10.1007/s00299-0172236-7.

52. Lawal, U.; Mediani, A.; H., M.; Shaari, K.; Ismail, I.S.; Khatib, A.; Abas, F. Metabolite profiling of Ipomoea aquatica at different growth stages in correlation to the antioxidant and $\alpha$-glucosidase inhibitory activities elucidated by $1 \mathrm{H}$ NMR-based metabolomics. Sci. Hortic. (Amsterdam). 2015, 192, 400-408, doi: 10.1016/j.scienta.2015.06.036.

53. Zheng, L.; Wang, M.; Ibarra-Estrada, E.; Wu, C.; Wilson, E.; Verpoorte, R.; Klinkhamer, P.; Choi, Y. Investigation of Chemomarkers of Astragali Radix of Different Ages and Geographical Origin by NMR Profiling. Molecules 2015, 20, 3389-3405, doi: 10.3390/molecules20023389.

54. Ossipov, V.; Ossipova, S.; Bykov, V.; Oksanen, E.; Koricheva, J.; Haukioja, E. Application of metabolomics to genotype and phenotype discrimination of birch trees grown in a long-term open-field experiment. Metabolomics 2008, 4, 39-51, doi:10.1007/s11306-007-0097-8.

55. Tan, L.; Jin, Z.; Ge, Y.; Nadeem, H.; Cheng, Z.; Azeem, F.; Zhan, R. Comprehensive ESI-Q TRAP-MS/MS based characterization of metabolome of two mango (Mangifera indica L) cultivars from China. Sci. Rep. 2020, 10, 20017, doi:10.1038/s41598-020-75636-y.

56. Vasmatkar, P.; Kaur, K.; Pannu, P.P.S.; Kaur, G.; Kaur, H. Unraveling the metabolite signatures of maize genotypes showing differential response towards southern corn leaf blight by 1H-NMR and FTIR spectroscopy. Physiol. Mol. Plant Pathol. 2019, 108, 101441, doi: 10.1016/j.pmpp.2019.101441.

57. Billet, K.; Houillé, B.; Dugé de Bernonville, T.; Besseau, S.; Oudin, A.; Courdavault, V.; Delanoue, G.; Guérin, L.; Clastre, M.; Giglioli-Guivarc'h, N.; et al. Field-Based Metabolomics of Vitis vinifera L. Stems Provides New Insights for Genotype Discrimination and Polyphenol Metabolism Structuring. Front. Plant Sci. 2018, 9, 798, doi: 10.3389/fpls.2018.00798.

58. Bundy, J. G.; Davey, M. P.; Viant, m. R. Environmental metabolomics: a critical review and future perspectives. Metabolomics 2009, 5, 3-21, doi: 10.1007/s11306-008-0152-0.

59. Rosati, A.; Cafiero, C.; Paoletti, A.; Alfei, B.; Caporali, S.; Casciani, L.; Valentini, M. Effect of agronomical practices on carpology, fruit and oil composition, and oil sensory properties, in olive (Olea europaea L.). Food Chem. 2014, 159, 236-243, doi:10.1016/j.foodchem.2014.03.014.

60. Guodong, R.; Xiaoxia, L.; Weiwei, Z.; Wenjun, W.; Jianguo, Z. Metabolomics reveals variation and correlation among different tissues of olive (Olea europaea L.). Biol. Open 2017, 6, 1317 LP - 1323, doi:10.1242/bio.025585.

61. Merchak, N.; El Bacha, E.; Bou Khouzam, R.; Rizk, T.; Akoka, S.; Bejjani, J. Geoclimatic, morphological, and temporal effects on Lebanese olive oils composition and classification: A 1H NMR metabolomic study. Food Chem. 2017, 217, 379-388, doi:10.1016/j.foodchem.2016.08.110.

62. Rongai, D.; Sabatini, N.; Del Coco, L.; Perri, E.; Del Re, P.; Simone, N.; Marchegiani, D.; Fanizzi, F. 1H NMR and Multivariate Analysis for Geographic Characterization of Commercial Extra Virgin Olive Oil: A Possible Correlation with Climate Data. Foods 2017, 6, 96, doi:10.3390/foods6110096. 
63. Culeddu, N.; Chessa, M.; Bandino, G.; Sedda, P.; Zurru, R.; Anedda, R.; Motroni, A.; Molinu, M.G.; Dettori, S.; Santona, M. Classification of Monovarietal Sardinian Extra Virgin Olive Oils by 1H NMR Metabolomic. Eur. J. Lipid Sci. Technol. 2017, 119, 1700035, doi: 10.1002/ejlt.201700035.

64. Kim, H.K.; Choi, Y.H.; Verpoorte, R. NMR-based metabolomic analysis of plants. Nat. Protoc. 2010, 5, 536-549, doi:10.1038/nprot.2009.237.

65. Mahrous, E.A.; Farag, M.A. Two dimensional NMR spectroscopic approaches for exploring plant metabolome: A review. J. Adv. Res. 2015, 6, 3-15, doi: 10.1016/j.jare.2014.10.003.

66. López-Escudero, F. J., del Río, C., Caballero, J. M., and Blanco-López, M. A.. Evaluation of olive cultivars for resistance to Verticillium dahliae. Eur. J. Plant Pathol. 2004, 110, 79-85. doi: 10.1023/B:EJPP.0000010150.08098.2d.

67. Martos-Moreno, C., Lòpez-Escudero, F. J., and Blanco-Lòpez, M. A. Resistance of olive cultivars to the defoliating pathotype of Verticillium dahliae. HortScience 2006, 41, 1313-1316. doi: 10.21273/HORTSCI.41.5.1313.

68. D’ Attoma, G., Morelli, M., Saldarelli, P., Saponari, M., Giampetruzzi, A., Boscia, D., et al. Ionomic differences between susceptible and resistant olive cultivars infected by Xylella fastidiosa in the outbreak area of Salento. Italy. Pathogens 2019, 8, 272. doi: 10.3390/pathogens8040272.

69. Vergine, M., Meyer, J. B., Cardinale, M., Sabella, E., Hartmann, M., Cherubini, P., et al. (2020). The Xylella fastidiosa-resistant olive cultivar "Leccino" has stable endophytic microbiota during the olive quick decline syndrome (OQDS). Pathogens 9:35. doi: 10.3390/pathogens9010035.

70. Luvisi, A.; Aprile, A.; Sabella, E.; Vergine, M.; Nicolì, F.; Nutricati, E.; Miceli, A.; Negro, C.; Bellis, L. de Xylella fastidiosa subsp. pauca (CoDiRO strain) infection in four olive (Olea europaea L.) cultivars: profile of phenolic compounds in leaves and progression of leaf scorch symptoms. Phytopathol. Mediterr. 2017, 56, 259-273, doi:10.14601/PHYTOPATHOL_MEDITERR-20578.

71. Girelli, C.R.; Del Coco, L.; Scortichini, M.; Petriccione, M.; Zampella, L.; Mastrobuoni, F.; Cesari, G.; Bertaccini, A.; D’Amico, G.; Contaldo, N.; et al. Xylella fastidiosa and olive quick decline syndrome (CoDiRO) in Salento (southern Italy): a chemometric $1 \mathrm{H}$ NMR-based preliminary study on Ogliarola salentina and Cellina di Nardò cultivars. Chem. Biol. Technol. Agric. 2017, 4, 25, doi:10.1186/s40538-017-0107-7.

72. Girelli; Angilè; Del Coco; Migoni; Zampella; Marcelletti; Cristella; Marangi; Scortichini; Fanizzi 1H-NMR Metabolite Fingerprinting Analysis Reveals a Disease Biomarker and a Field Treatment Response in Xylella fastidiosa subsp. pauca-Infected Olive Trees. Plants 2019, 8, 115, doi:10.3390/plants8050115.

73. Markakis, E.A.; Tjamos, S.E.; Antoniou, P.P.; Roussos, P.A.; Paplomatas, E.J.; Tjamos, E.C. Phenolic responses of resistant and susceptible olive cultivars induced by defoliating and nondefoliating Verticillium dahliae pathotypes. Plant Dis. 2010, 94, 11561162, doi:10.1094/PDIS-94-9-1156. 